$10-1-2012$

\title{
Visual Function after Correction of Distance Refractive Error with Ready-made and Custom Spectacles: A Randomized Clinical Trial.
}

Christopher J. Brady

Wills Eye Institute

Andrea C Villanti

Johns Hopkins University

Monica Gandhi

Dr. Shroff's Charity Eye Hospital, Delhi, India

David S Friedman

Johns Hopkins University

Lisa Keay

Johns Hopkins University

Follow this and additional works at: https://jdc.jefferson.edu/willsfp

Part of the Ophthalmology Commons

Let us know how access to this document benefits you

\section{Recommended Citation}

Brady, Christopher J.; Villanti, Andrea C; Gandhi, Monica; Friedman, David S; and Keay, Lisa, "Visual Function after Correction of Distance Refractive Error with Ready-made and Custom Spectacles: A Randomized Clinical Trial." (2012). Wills Eye Hospital Papers. Paper 14. https://jdc.jefferson.edu/willsfp/14

This Article is brought to you for free and open access by the Jefferson Digital Commons. The Jefferson Digital Commons is a service of Thomas Jefferson University's Center for Teaching and Learning (CTL). The Commons is a showcase for Jefferson books and journals, peer-reviewed scholarly publications, unique historical collections from the University archives, and teaching tools. The Jefferson Digital Commons allows researchers and interested readers anywhere in the world to learn about and keep up to date with Jefferson scholarship. This article has been accepted for inclusion in Wills Eye Hospital Papers by an authorized administrator of the Jefferson Digital Commons. For more information, please contact: JeffersonDigitalCommons@jefferson.edu. 


\title{
As submitted to:
}

\section{Ophthalmology}

\section{And later published as:}

\section{Visual function after correction of distance refractive error with ready-made and custom made spectacles - a randomized clinical trial}

\author{
Volume 119, Issue 10, October 2012, Pages 2014-2020
}

\section{DOI: 10.1016/j.ophtha.2012.03.051}

Christopher J. Brady, MD, ${ }^{1,2}$ Andrea C. Villanti, MPH PhD, ${ }^{3}$ Monica Gandhi, MD, ${ }^{5}$ David S. Friedman, MD PhD, ${ }^{1,6}$ and Lisa Keay, MPH PhD ${ }^{1,4}$

${ }^{1}$ Dana Center for Preventive Ophthalmology, Wilmer Eye Institute, Johns Hopkins University, Baltimore, Maryland, USA

${ }^{2}$ Wills Eye Institute, Thomas Jefferson University School of Medicine, Philadelphia, Pennsylvania, USA

${ }^{3}$ Department of Health, Behavior and Society, Bloomberg School of Public Health, Johns Hopkins University, Baltimore, Maryland, USA

${ }^{4}$ The George Institute for Global Health, University of Sydney, Sydney, Australia

${ }^{5}$ Dr. Shroff's Charity Eye Hospital, Delhi, India

${ }^{6}$ Department of International Health, Bloomberg School of Public Health, Johns Hopkins University, Baltimore, Maryland, USA

\section{Financial support:}

Support for this project was provided by Orbis International, NY; Australian National Health and Medical Research Council post doctoral fellowship (LK). The sponsor or funding organization had no role in the design or conduct of this research.

\section{Conflict of Interest:}

No conflicting relationship exists for any author.

Running head: Visual function with ready-made and custom spectacles 
Address for reprints:

Christopher J. Brady, MD

Wills Eye Institute

Thomas Jefferson University School of Medicine

840 Walnut Street, Suite 800

Philadelphia, PA 19107

E-mail: brady@jhmi.edu 


\section{Abstract}

Purpose: To evaluate patient-reported outcome measures with the use of ready-made spectacles (RMS) and custom spectacles (CS) in an adult population in India with uncorrected refractive error (URE).

Design: Prospective double-masked randomized trial with one month follow-up.

Participants: 363 adults aged $18-45$ years with $\geq 1$ diopter (D) of URE (RMS, $n=183 ; C S, n=$ 180).

Intervention: All participants received complete refraction, and were randomized to receive CS (full sphero-cylindrical correction) or RMS based on the spherical equivalent for the eye with lower refractive error but limited to the powers in the RMS inventory.

Main Outcome Measures: Visual Function and Quality of Life instrument (VFQoL), participant satisfaction.

Results: Rasch scores for VFQoL increased from 1.14 to 4.37 logits in the RMS group, and from 1.11 to 4.72 logits in the CS group (Respective mean change 3.23 (95\% Confidence Interval (Cl): $2.90-3.56)$ vs. $3.61(95 \% \mathrm{Cl}$ : 3.34-3.88)). Mean patient satisfaction also increased by $1.83(95 \% \mathrm{Cl}: 1.60-2.06)$ points on a 5-point Likert scale in the RMS group and 2.04 (95\% Cl: 1.83-2.24) points in the CS group. In bivariate analyses, CS was not associated increased VFQoL or patient satisfaction compared to RMS group. In the full multivariable linear regression, the CS group had greater improvement when compared to these receiving RMS $(+0.45$ logits; $95 \% \mathrm{Cl}: 0.02-0.88)$, and subjects with astigmatism $>2.00 \mathrm{D}$ had significantly less improvement (-0.99 logits; $95 \% \mathrm{Cl}:-1.68$ - -0.30) after controlling for demographic and visionrelated characteristics. In multivariable analysis, increased change in patient satisfaction was related to demographic and optical characteristics, but not spectacle group.

Conclusions: Ready-made spectacles produce large, but slightly smaller improvements in visual function and quality of life, and similar satisfaction with vision at one-month follow-up when compared to custom spectacles. RMS are suitable for the majority of individuals with URE in our study population, though those with high degrees of astigmatism may benefit from a trial of CS. This study provides further evidence for use of ready-made spectacles in settings where custom spectacles are unavailable, unaffordable, or refractive services are inaccessible to those in need. 
Regulatory and funding agencies are increasingly calling for the use of patient-reported outcome measures in all fields of healthcare. ${ }^{1-3}$ Within ophthalmology, many instruments are in use for measuring disability and quality of life related to cataracts, ${ }^{4}$ diabetic retinopathy, ${ }^{5}$ agerelated macular degeneration, ${ }^{6}$ glaucoma, ${ }^{7}$ and refractive error. ${ }^{8}$

Uncorrected refractive error (URE) is a major cause of visual impairment and blindness worldwide. It is estimated that between 98-153 million people have distance vision worse than 20/60 due to URE. 9, 10 Such impairments are associated with decreased quality of life and visual function. ${ }^{11-13}$ Accordingly, the WHO has made refractive error correction a priority in their global campaign to eliminate global blindness: Vision 2020 - The Right to Sight. ${ }^{14,15}$ The burden of URE is disproportionately borne by persons living in developing countries, ${ }^{15,16}$ with nearly a quarter of those with distance visual impairment living in India. ${ }^{9}$ The global economic burden of URE has been estimated at $\$ 269$ billion dollars in productivity losses, and provision of care for affected individuals. ${ }^{17,18}$

Although the treatment of refractive error with spectacles is technically straightforward, poor access to refractive services and high costs limit universal correction in the developing world. ${ }^{19-}$ ${ }^{21}$ Academic, private and humanitarian groups are engaged in spectacle provision for both ametropia and presbyopia in developing countries, some of whom have utilized ready-made spectacles (RMS) ${ }^{22-25}$ The cost of refractive error correction is partially driven by the fact that custom spectacles (CS) need to be made to order with unique spherical and cylindrical power for each eye, and frequently cannot be dispensed at the time of prescribing. RMS can be factory made in bulk using the same spherical power in both eyes, in limited diopter steps, frame sizes and styles. RMS can be dispensed immediately as long as the appropriate inventory is maintained. Theoretically the majority of a population should have acceptable vision with RMS. ${ }^{26-28}$ We have recently reported visual acuity and patient-reported planned continued use of RMS compared with CS in children in China ${ }^{25,29}$ and adults in India, ${ }^{24}$ and found a comparable degree of acceptability.

In order to determine if RMS are acceptable to a population, validated patient-reported outcome measures play a critical role. We recently reported the validation of a novel visual function and quality of life instrument using Rasch analysis in an urban Indian population. ${ }^{30}$ In the present study, we use this instrument to compare RMS versus CS in a randomized, prospective, doublemasked trial in Delhi, India.

\section{Subjects and Methods}

The study design has been described in detail elsewhere. ${ }^{24}$ Briefly, the performance of RMS was compared with CS using a prospective, short term (1-month) double-masked randomized clinical trial. The Johns Hopkins Medicine Institutional Review Board and the Dr Shroff's Charity Eye Hospital (SCEH) Human Research Ethics Committee approved the study protocol and this clinical trial was registered with the US National Institutes of Health Protocol Registration System (http://clinicaltrials.gov NCT00657670; last accessed 3/2/2012). The research adhered to the tenets of the Declaration of Helsinki.

Between May and September 2008, 400 adults presenting for care at the SCEH clinic and outreach screening camps in Delhi, India were recruited for participation in this study. All participants were refracted prior to study enrollment using a standardized protocol ${ }^{24}$ and randomized to receive either the CS prescription based on the full sphero-cylindrical correction or RMS prescription based on the spherical equivalent (SE) for the eye with lower refractive error but limited to the 25 powers in the RMS inventory. Eligible participants were 18-45 years of age, had habitual vision of 20/40 or worse in the better-seeing eye, at least 1 diopter (D) of 
spherical refractive error and were willing to return for follow-up study visits. Study follow-up was conducted at one-month. Study enrollment and follow-up are summarized in Figure 1. Of the initial 400 participants, 10 were excluded due to presenting vision $>20 / 40$ and 27 were lost to follow-up; this analysis is limited to the 363 eligible participants (RMS, $n=183$; CS, $n=180$ ) with baseline and follow-up measures. We used an intent-to-treat approach. There were nine errors in spectacle orders whereby 7 participants allocated to RMS received their full correction and 2 allocated to CS received bilateral spheres. Data analyses were repeated for treatment received. We did not impute outcome measures to address missing follow-up data.

\section{Randomization}

The research optometrists, coordinator and study subjects were masked to the allocation of spectacles and remained masked during all visits. After completion of the randomization visit, both the CS and RMS prescriptions, pupillary distance, frame choice and participant identification number were sent to the dispensing optical shop. The optical technician then referred to a computer-generated randomization grid (www.randomization.com accessed April 1,2008 ) with 400 entries and ordered the spectacles according to the group allocation for the specific participant identification number. There was no opportunity for the optical shop technician to change a subject's identification number or move the participant to a different location on the randomization table. The spectacles were verified as ordered by a technician at the optical shop prior to being dispensed. Masking was maintained during all follow-up assessments because the spectacles were manufactured at an optical facility separate from the testing site, and the RMS and CS were identical in gross appearance. Additionally, those involved in data collection were not equipped to measure refractive power of the spectacles during assessment and thereby remained masked to the treatment allocation during all evaluations.

\section{Outcome measures}

Primary outcome measures for this analysis were patient responses to a Visual Function and Quality of Life Instrument validated in this population ${ }^{30}$ and participant satisfaction. The 16-item Visual Function and Quality of Life Instrument was developed from the 20-item Garamendimodified Refractive Status and Vision Profile ${ }^{31}$ and the 12-item Fletcher Quality of Life scale ${ }^{32}$ was piloted, modified, and validated using Rasch analysis. Logit scores from Rasch analysis of the 16-item questionnaire provided an interval measure of participant ability, including mobility, social interaction, and visual symptoms at baseline and follow-up. ${ }^{30}$ Patient satisfaction was assessed on a five-point Likert scale using the question "During the past four weeks, how satisfied have you been with your vision?" where $0=$ Very dissatisfied, $1=$ Dissatisfied, $2=$ Neither satisfied nor dissatisfied, $3=$ Satisfied, and $4=$ Very satisfied. A secondary outcome in this analysis was distance visual acuity. Visual acuity was measured using tumbling E-charts (Precision Vision, Villa Park, IL, USA) with retro-illumination. Visual acuity was scored with 0.02 logMAR (logarithm of Minimum Angle of Resolution) assigned to each letter. All measures were assessed at baseline and follow-up.

\section{Statistical design and methods}

The primary objective of the analysis was to determine whether receipt of ready-made or custom-made spectacles affected patient-reported visual function and quality of life and visionrelated satisfaction. Responses were scored using Rasch analysis (Andrich model) in WinSteps software (ver. 3.67, Chicago, IL) to produce interval scores for each participant based on their responses to the 16-item Visual Function and Quality of Life Instrument at baseline and onemonth follow-up. All other analyses were conducted in Stata 11 (College Station, Texas). Chisquare tests assessed the difference in distributions of Rasch scores between groups at baseline and follow-up. To evaluate differences in mean outcome measures between the RMS 
and CS group for baseline, follow-up, and change measures, we used t-tests with a significant Type I error rate of $5 \%$. We had pre-specified secondary analyses of the impact of astigmatism and anisometropia on the effect size in the study protocol and thus, sensitivity analyses were conducted to determine mean differences in patient-reported outcomes between study groups among participants with astigmatism $\geq 2.00 \mathrm{D}$ and anisometropia $\geq 1.00 \mathrm{D}$. Multivariable analyses were conducted to examine the effect of group on change in Rasch score and patient satisfaction, controlling for residual confounding by demographic and vision-related characteristics. Interaction terms were introduced to the final multivariable regression models for both outcomes to test for the presence of effect modification by astigmatism or anisometropia.

The study was powered to be able to detect a $15 \%$ difference in the primary outcome of the overall study (rate of continued use of spectacles) at a $5 \%$ level of significance with $80 \%$ power assuming base rate of continued use of $70 \%$. We enrolled 200 subjects into each arm assuming a loss to follow-up rate of $10-15 \%$ to provide a target 175 in each arm. Our pilot data for the patient reported outcomes instrument ${ }^{30}$ suggested we would be able to measure a difference of 0.5 logits (power $80 \%$, statistical significance $5 \%$ ) with this sample size.

\section{Results}

The average age in our study population was 30.4 years and nearly $60 \%$ were female. Participants were generally healthy with few comorbidities. Approximately $55 \%$ of the population reported education at the secondary level or below and $79 \%$ had annual household income less than 60,000 Indian Rupees (RP; approximately United States Dollars (USD)=1500). Though more than half had worn spectacles previously, their presenting vision was on average $20 / 70^{+1}$ (logMAR $\left.=0.56\right)$. A small proportion had complex refractive error such as anisometropia ( $8 \%$ ) and $12 \%$ had more than 2 diopters of astigmatism (Table 1$)$. The only significant difference between the two intervention groups was that the custom spectacle group was more likely to have reported seeing an ophthalmologist before.

The distribution of Rasch scores for the Visual Function and Quality of Life instrument are presented in Figure 2, panel A and B by study group and time of assessment. Lower scores represent worse function and reduced quality of life. At baseline, the Rasch scores were approximately normally distributed and did not differ between groups (Chi-square $p=0.567$ ). The second panel in the figure demonstrates left-skewed Rasch scores representing an increase in visual function and quality of life over the one-month follow-up; there was no difference in distribution of Rasch follow-up scores between the RMS and CS groups (Chisquare $p=0.600$ ).

Mean Rasch scores, and patient satisfaction Likert scale scores did not differ between study groups as measured at baseline, one-month follow-up or by assessing change in outcome from baseline to follow-up. In the full sample, visual function and quality of life increased by an average of 3.23 logits (95\% Confidence Interval $(\mathrm{Cl}): 2.90-3.56)$ in the RMS group and an average of 3.61 logits (95\% Cl: 3.34-3.88) in the CS group. Mean patient satisfaction also increased by 1.83 points (95\% Cl: $1.60-2.06)$ on the Likert scale in the RMS group and 2.04 points $(95 \% \mathrm{Cl}: 1.83-2.24)$ in the CS group. While there was not a statistically significant difference at follow-up in mean change for Rasch score and satisfaction between study groups in stratified analyses of participants with astigmatism or anisometropia, the magnitude of these changes was larger in the CS group. A change of 0.1 logMAR in visual acuity, which represents one line on a Snellen chart, was associated with a 2.71 logit increase in Rasch score over the study period $(p<0.001)$ (Figure 3). 
Results from bivariate analyses of demographic and vision-related characteristics and change in Rasch score are presented as unadjusted regression coefficients in Table 2 . The only significant predictor of change in Rasch score in the bivariate analyses was astigmatism greater than two diopters in both eyes. In the multivariable linear regression model, the custom spectacles group reported marginally significant improvements in visual function and quality of life compared to the ready-made spectacles group, equivalent to a 0.45 logit increase in the Rasch score (95\% Cl: $0.02-0.88)$, controlling for age, gender, marital status, education, household income, astigmatism greater than two diopters in both eyes, anisometropia greater than one diopter, pupil size greater than four millimeters, and presenting vision worse than $20 / 63$ in the better-seeing eye. In addition, astigmatism greater than two diopters in both eyes at baseline was negatively associated with change in visual function and quality of life, controlling for all other variables in the model (-0.99 logits; $95 \% \mathrm{Cl}:-1.68--0.30)$. Tests for interaction indicate that there was statistically significantly improved visual function and quality of life among those with custom spectacles compared to RMS in those with astigmatism (2.00 logits; 95\% Cl: $0.72-3.28$ ) and anisometropia (2.13 logits; $95 \% \mathrm{Cl}: 0.62-3.64)$ (model not shown).

Bivariate and multivariable linear regression models for change in satisfaction were also developed. Intervention group was not a significant predictor of change in satisfaction in either model. In bivariate analyses of demographic and vision-related characteristics, education, household income, pupil size greater than four millimeters, and astigmatism greater than two diopters in both eyes were negatively associated with change in satisfaction. In the full multivariable model, income $60,000-120,000$ RP compared to income $<60,000$ RP $(-0.50$ points; $95 \% \mathrm{Cl}:-0.96--0.04)$, astigmatism greater than two diopters in both eyes $(-0.72$ points; $95 \% \mathrm{Cl}$ : $-1.21-0.23)$, and pupil size greater than 4 millimeters $(-0.33$ points; $95 \% \mathrm{Cl}$ : $-0.66--0.01)$ were negatively associated with change in satisfaction, controlling for all other variables in the model. The addition of an interaction term between study group and astigmatism to the full model indicates that there is a statistically significant increase in patient satisfaction among those with custom spectacles versus RMS in this subgroup (1.23 points; $95 \% \mathrm{Cl} ; 0.33-2.14$ ) (model not shown).

\section{Discussion}

This double-masked randomized clinical trial in urban India demonstrates that ready-made spectacles (RMS) produce similar changes in patient-reported outcomes of visual function, quality of life, and satisfaction with vision at one-month follow-up when compared to custom spectacles (CS). This is despite the fact that those in the RMS group did not have fully corrected vision. ${ }^{24}$ With our previous findings on the equivalent uptake of ready-made spectacles and custom spectacles in this population, ${ }^{24}$ this study supports more widespread use of ready-made spectacles in settings where custom spectacles are unavailable or unaffordable and refractive services are inaccessible to those in need.

The ability to use RMS as the foundation of outreach or humanitarian efforts to combat uncorrected refractive error is attractive for financial and practical reasons. Although the present study did not source actual RMS, the cost savings for the spectacles should be significant. ${ }^{22}$ Additionally the ability to dispense spectacles at the time of refraction allows for dramatically simplified logistics, as long as an appropriate inventory of RMS is maintained.

We previously estimated that approximately $10 \%$ of this population would have refractive needs that are not met by RMS. ${ }^{24,25}$ Additionally, a recent review of global epidemiologic studies found rates ranging from 15.8 to $48.9 \%$ for astigmatism greater than 0.5 to 1.0 diopters. ${ }^{33}$ In our 
study population, approximately $12 \%$ had astigmatism greater than 2.00 diopters, and this group had smaller gains in reported vision function and quality of life at follow-up, controlling for demographic and vision-related characteristics. Subgroup analyses show that there clearly are some who would be best served with custom spectacles. While these people are more likely to have higher degrees of astigmatism or anisometropia, the findings reported here and our prior reports from this dataset did not support the use of refractive cutoffs to exclude people from receiving RMS. Since RMS can be tried on immediately and worn in the vision testing setting, one could use this approach to identify persons who would not tolerate RMS well. Based on our findings, when integrating RMS into refractive service delivery, a mechanism should be in place to detect high levels of astigmatism and offer these individuals custom spectacles.

Visual function and quality of life was not associated with higher level of education or income, factors which could be associated with higher visual demand. Higher income and education were, however, associated with a reduced degree of improvement in satisfaction, though this was independent of treatment group assignment. It is still possible that individuals with unique spectacle needs could be expected to be the most discerning in a population, and so might be more likely to return for follow-up visits for dispensation should the decision to prescribe CS be made.

The use of a patient-reported outcome as a primary endpoint has pitfalls since it is, by its very nature, subjective. By using Rasch analysis to validate our visual function questionnaire, ${ }^{30}$ we have demonstrated that our instrument is valid, mathematically robust, and well-targeted to this population. We showed a clinically important improvement in Rasch score of 3.23 and 3.61 logits in the RMS and CS groups respectively. This magnitude of this improvement is in line with change in logits after cataract extraction. ${ }^{4}$

Additionally, results from our subgroup analyses show that there is a larger absolute difference between the change in Rasch scores in the CS compared to the RMS group within those patients with astigmatism $>2.00 \mathrm{D}$ or anisometropia $>1.00 \mathrm{D}$. This provides a degree of face validity. Moreover, there was a clear positive linear relationship between improvement in visual acuity and improvement in Rasch score, demonstrating that our measure also has criterion validity. We had 21 subjects with astigmatism in both the RMS and CS groups and 15 subjects with anisometropia in both groups. While the findings of our study suggest improved patient satisfaction and vision-related quality of life in the CS group compared to the RMS group among the small number of participants with astigmatism or anisometropia, the study was underpowered to detect a clinically meaningful difference in these subgroups. Future studies with targeted recruitment of participants with astigmatism and anisometropia are needed to confirm that CS is preferable to RMS in these subgroups before designing programs without a "try-before-you-buy" option. Future research might also seek to address whether individuals with higher visual demand, either recreationally or professionally, have a preference for CS in the setting of astigmatism or anisometropia. Future research should seek to attain longer follow-up as long-term spectacle acceptance may not mirror our 1 month results. ${ }^{34}$

Important strengths of the study include randomized design, large sample size, low loss to follow-up, and use of validated visual function instrument.

In conclusion, this research demonstrates similar large improvements in patient reported visual function with the provision of either ready-made or custom spectacles. We believe that the acceptability and affordability support the provision of RMS in those settings where CS are impractical, or where the cost of which would limit the number of those who could benefit. As resources permit, and access to refractive services improve, we expect more people opting to 
pay a premium for custom spectacles, but until that time, we predict high levels of satisfaction with ready-made spectacles. 


\section{References}

1. Hobart JC, Cano SJ, Zajicek JP, Thompson AJ. Rating scales as outcome measures for clinical trials in neurology: problems, solutions, and recommendations. Lancet Neurol 2007;6:1094-105.

2. U.S. Department of Health and Human Services FDA Center for Drug Evaluation and Research, U.S. Department of Health and Human Services FDA Center for Biologics Evaluation and Research, U.S. Department of Health and Human Services FDA Center for Devices and Radiological Health. Guidance for industry: patientreported outcome measures: use in medical product development to support labeling claims: draft guidance. Health Qual Life Outcomes [serial online] $2006 ; 4: 79$. Available at: http://www.hqlo.com/content/pdf/1477-7525-4-79.pdf. Accessed March 27, 2012.

3. Garratt A, Schmidt L, Mackintosh A, Fitzpatrick R. Quality of life measurement: bibliographic study of patient assessed health outcome measures [report online]. BMJ 2002;324:1417. Available at:

http://www.bmj.com/highwire/filestream/361992/field_highwire_art icle_pdf/0.pdf. Accessed March 27, 2012.

4. Lamoureux EL, Fenwick E, Pesudovs K, Tan D. The impact of cataract surgery on quality of life. Curr Opin Ophthalmol $2011 ; 22: 19-27$.

5. Mazhar K, Varma R, Choudhury F, et al, Los Angeles Latino Eye Study Group. Severity of diabetic retinopathy and healthrelated quality of life: the Los Angeles Latino Eye Study . Ophthalmology 2011;118:649-55.

6. Cahill MT, Banks AD, stinnett SS, Toth CA. Vision-related quality of life in patients with bilateral severe age-related macular degeneration. Ophthalmology 2005;112:152-8. 
7. Mckean-Cowdin R, Wang $Y$, Wu J, et al, Los Angeles Latino Eye Study Group. Impact of visual field loss on health-related quality of life in glaucoma: the Los Angeles Latino Eye Study . Ophthalmology 2008;115:941-8.

8. Pesudovs K, Garamendi E, Elliott DB. The Quality of Life Impact of Refractive Correction (QIRC) Questionnaire: development and validation. Optom Vis Sci 2004;81:769-77. 9. Dandona L, Dandona R. What is the global burden of visual impairment? BMC Med [serial online] 2006;4:6. Available at: http://www.biomedcentral.com/1741-7015/4/6. Accessed March 27, 2012 .

10. Resnikoff S, Pascolini D, Mariotti SP, Pokharel GP. Global magnitude of visual impairment caused by uncorrected refractive errors in 2004. Bull World Health Organ 2008;86:63-70.

11. Uribe JA, Swenor BK, Munoz BE, West SK. Uncorrected refractive error in a Latino population: Proyecto VER. Ophthalmology 2011;118:805-11.

12. Vincent JE, Pearce MG, Leasher $\mathrm{J}$, et al. The rationale for shifting from a voluntary clinical approach to a public health approach in addressing refractive errors. Clin Exp Optom $2007 ; 90: 429-33$.

13. Vu HT, Keeffe JE, McCarty CA, Taylor HR. Impact of unilateral and bilateral vision loss on quality of life. Br J Ophthalmol 2005;89:360-3.

14. Pizzarello L, Abiose A, Ffytche T, et al. VISION 2020: The Right to Sight: a global initiative to eliminate avoidable blindness. Arch Ophthalmol 2004;122:615-20.

15. Chandra SR. Global blindness: VISION 2020: the Right to Sight. Arch Ophthalmol 2008;126:1457.

16. Naidoo KS, Wallace DB, Holden BA, et al. The challenge of uncorrected refractive error: driving the agenda of the Durban 
Declaration on refractive error and service development. Clin Exp Optom 2010;93:131-6.

17. Smith TS, Frick KD, Holden BA, et al. Potential lost productivity resulting from the global burden of uncorrected refractive error. Bull World Health Organ 2009;87:431-7. 18. Holden BA, Fricke TR, Ho SM, et al. Global vision impairment due to uncorrected presbyopia. Arch Ophthalmol $2008 ; 126: 1731-9$.

19. Ayanniyi AA, Folorunso FN, Adepoju FG. Refractive ocular conditions and reasons for spectacles renewal in a resourcelimited economy. BMC Ophthalmol [serial online] 2010;10:12. Available at: http://www.biomedcentral.com/1471-2415/10/12. Accessed March 27, 2012.

20. Ramke J, du Toit R, Palagyi A, et al. Public sector refraction and spectacle dispensing in low-resource countries of the Western Pacific. Clin Experiment Ophthalmol 2008;36:339-47. 21. Ramke J, Palagyi A, du Toit R, Brian G. Using assessment of willingness to pay to improve a Cambodian spectacle service. Br J Ophthalmol 2008;92:170-4.

22. Ramke J, Palagyi A, du Toit R, Brian G. Applying standards to readymade spectacles used in low-resource countries. Optom Vis Sci 2009;86:1104-11.

23. Vincent JE. Simple spectacles for adult refugees on the Thailand-Burma border. Optom Vis Sci 2006;83:803-10.

24. Keay L, Gandhi M, Brady C, et al. A randomized clinical trial to evaluate ready-made spectacles in an adult population in India. Int J Epidemiol 2010;39:877-88.

25. Zeng $Y$, Keay L, He M, et al. A randomized, clinical trial evaluating ready-made and custom spectacles delivered via a school-based screening program in China. Ophthalmology $2009 ; 116: 1839-45$. 
26. Maini R, Keeffe J, Weih LA, et al. Correction of refractive error in the Victorian population: the feasibility of "off the shelf" spectacles. Br J Ophthalmol 2001;85:1283-6.

27. du Toit R, Ramke J, Brian G. Tolerance to prism induced by readymade spectacles: setting and using a standard. Optom Vis Sci 2007;84:1053-9.

28. Bourne RR, Dineen BP, Huq DM, et al. Correction of refractive error in the adult population of Bangladesh: meeting the unmet need. Invest Ophthalmol Vis Sci 2004;45:410-7. 29. Keay L, Zeng Y, Munoz B, et al. Predictors of early acceptance of free spectacles provided to junior high school students in China. Arch Ophthalmol 2010;128:1328-34. 30. Brady CJ, Keay L, Villanti A, et al. Validation of a visual function and quality of life instrument in an urban Indian population with uncorrected refractive error using Rasch analysis. Ophthalmic Epidemiol 2010;17:282-91.

31. Garamendi E, Pesudovs K, Stevens MJ, Elliott DB. The Refractive Status and Vision Profile: evaluation of psychometric properties and comparison of Rasch and summated Likert-scaling. Vision Res 2006;46:1375-83.

32. Fletcher AE, Ellwein LB, Selvaraj S, et al. Measurements of vision function and quality of life in patients with cataracts in southern India: report of instrument development. Arch Ophthalmol 1997;115:767-74.

33. Ezelum C, Razavi H, Sivasubramaniam S, et al, Nigeria National Blindness and Visual Impairment Study Group. Refractive error in Nigerian adults: prevalence, type, and spectacle coverage. Invest Ophthalmol Vis Sci 2011;52:5449-56. 34. Vincent JE, Netek S, Parry A, et al. Reported wearing compliance of ready-made spectacles at 6 and 12 months. Optom Vis Sci 2010;87:958-65. 
Table 1. Characteristics of study participants at baseline $(n=363)$.

\begin{tabular}{|c|c|c|c|c|}
\hline & \multicolumn{2}{|c|}{$\begin{array}{l}\text { Ready-made } \\
\text { spectacles } \\
(\mathrm{n}=183)\end{array}$} & \multicolumn{2}{|c|}{$\begin{array}{l}\text { Custom } \\
\text { spectacles } \\
(\mathrm{n}=180)\end{array}$} \\
\hline & $\mathrm{n}$ & $(\%)$ & $\mathrm{n}$ & $(\%)$ \\
\hline \multicolumn{5}{|l|}{ Demographic characteristics } \\
\hline Age, mean (SD) & 30.36 & $(9.39)$ & 30.41 & $(8.93)$ \\
\hline Male & 75 & $(40.98)$ & 79 & $(43.89)$ \\
\hline Married & 103 & $(56.28)$ & 102 & $(56.67)$ \\
\hline \multicolumn{5}{|l|}{ Education } \\
\hline Illiterate & 27 & $(14.75)$ & 23 & $(12.78)$ \\
\hline Primary school & 43 & $(23.50)$ & 41 & $(22.78)$ \\
\hline Secondary school & 36 & $(19.67)$ & 30 & $(16.67)$ \\
\hline Higher secondary school & 30 & $(16.39)$ & 35 & $(19.44)$ \\
\hline Graduate, post-graduate, professional school & 47 & (25.68) & 51 & $(28.33)$ \\
\hline \multicolumn{5}{|l|}{ Annual household income in Indian Rupees (RP) } \\
\hline$<60,000 \mathrm{RP}(<$ USD $\$ 1500)$ & 145 & $(79.23)$ & 136 & $(75.56)$ \\
\hline 60,000 - 120,000 RP (USD $\$ 1500$ - 3000) & 20 & $(10.93)$ & 29 & $(16.11)$ \\
\hline$>120,000 \mathrm{RP}(>$ USD $\$ 3000)$ & 13 & $(7.10)$ & 12 & $(6.67)$ \\
\hline \multicolumn{5}{|l|}{ Health-related characteristics } \\
\hline \multicolumn{5}{|l|}{ General rating of health } \\
\hline Excellent & 9 & $(4.82)$ & 11 & $(6.11)$ \\
\hline Very good & 19 & $(10.38)$ & 14 & $(7.78)$ \\
\hline Fair & 39 & $(21.31)$ & 41 & $(22.78)$ \\
\hline Poor & 116 & $(63.39)$ & 114 & $(63.33)$ \\
\hline Ever smoke tobacco & 14 & $(7.65)$ & 13 & $(7.22)$ \\
\hline Ever drink alcohol & 11 & $(6.01)$ & 6 & $(3.33)$ \\
\hline Hypertension, diabetes or heart disease & 6 & $(3.28)$ & 3 & $(1.67)$ \\
\hline \multicolumn{5}{|l|}{ Vision-related characteristics } \\
\hline Ever seen ophthalmologist & 99 & $(54.10)$ & 128 & (71.11) \\
\hline $\begin{array}{l}\text { Ever worn spectacles } \\
\text { Uncorrected vision in better eye at baseline, mean }\end{array}$ & 102 & $(55.74)$ & 104 & $(58.10)$ \\
\hline $\begin{array}{l}\text { logMAR (SD) } \\
\text { Uncorrected vision in worse eye at baseline, mean }\end{array}$ & 0.56 & $(0.21)$ & 0.57 & $(0.21)$ \\
\hline $\operatorname{logMAR}(S D)$ & 0.60 & $(0.21)$ & 0.62 & $(0.22)$ \\
\hline Astigmatism $\geq 2.00 \mathrm{D}$ in both eyes & 21 & $(11.48)$ & 21 & $(11.67)$ \\
\hline $\begin{array}{l}\text { Anisometropia } \geq 1.00 \mathrm{D} \\
\text { Anisometropia } \geq 1.00 \mathrm{D} \text { and } \geq 2.00 \mathrm{D} \text { astigmatism in } \\
\text { both eyes }\end{array}$ & $\begin{array}{l}15 \\
35\end{array}$ & $\begin{array}{l}(8.20) \\
(19.13)\end{array}$ & $\begin{array}{l}15 \\
31\end{array}$ & $\begin{array}{l}(8.33) \\
(17.22)\end{array}$ \\
\hline
\end{tabular}

Missing data: age (1 Ready Made Spectacles (RMS), 1 Custom (CS)), income (5 RMS, 3 CS). Bold values indicate $p$ $<0.05$. SD = standard deviation, RP = Indian Rupees, USD = United States Dollars, logMAR = logarithm of the minimum angle of resolution, $\mathrm{D}=$ diopters. 
Table 2. Linear regression of change in Rasch score and satisfaction

\begin{tabular}{|c|c|c|c|c|c|c|c|c|}
\hline & \multicolumn{4}{|c|}{ Change in Rasch score } & \multicolumn{4}{|c|}{ Change in satisfaction } \\
\hline & \multicolumn{2}{|c|}{ Unadjusted } & \multicolumn{2}{|c|}{ Adjusted } & \multicolumn{2}{|c|}{ Unadjusted } & \multicolumn{2}{|c|}{ Adjusted } \\
\hline & Coeff. & $(95 \% \mathrm{Cl})$ & Coeff. & $(95 \% \mathrm{Cl})$ & Coeff. & $(95 \% \mathrm{Cl})$ & Coeff. & $(95 \% \mathrm{Cl})$ \\
\hline \multicolumn{9}{|l|}{ Study group } \\
\hline Ready-made spectacles & Ref. & & Ref. & & Ref. & & Ref. & \\
\hline Custom spectacles & 0.38 & $(-0.05-0.80)$ & 0.45 & $(0.02-0.88)$ & 0.21 & $(-0.10-0.51)$ & 0.22 & $(-0.08-0.53)$ \\
\hline Age & 0.02 & $(0.00-0.04)$ & 0.01 & $(-0.02-0.05)$ & 0.01 & $(-0.01-0.03)$ & 0.00 & $(-0.02-0.03)$ \\
\hline Female & Ref. & & Ref. & & Ref. & & Ref. & \\
\hline Male & -0.29 & $(-0.72-0.14)$ & -0.22 & $(-0.68-0.23)$ & -0.21 & $(-0.52-0.10)$ & -0.14 & $(-0.46-0.18)$ \\
\hline \multicolumn{9}{|l|}{ Marital status } \\
\hline Married & Ref. & & Ref. & & Ref. & & Ref. & \\
\hline Single & -0.37 & $(-0.80-0.06)$ & -0.07 & $(-0.73-0.59)$ & -0.22 & $(-0.53-0.09)$ & -0.03 & $(-0.50-0.44)$ \\
\hline \multicolumn{9}{|l|}{ Education } \\
\hline Primary school & -0.12 & $(-0.84-0.61)$ & 0.11 & $(-0.65-0.87)$ & 0.01 & $(-0.51-0.53)$ & 0.17 & $(-0.37-0.71)$ \\
\hline Secondary school & -0.35 & $(-1.11-0.41)$ & 0.02 & $(-0.81-0.84)$ & -0.24 & $(-0.78-0.30)$ & -0.01 & $(-0.60-0.58)$ \\
\hline Higher secondary school & -0.62 & $(-1.39-0.14)$ & -0.29 & $(-1.15-0.57)$ & -0.29 & $(-0.83-0.26)$ & -0.04 & $(-0.66-0.57)$ \\
\hline Graduate, post-graduate, professional school & -0.32 & $(-1.03-0.38)$ & -0.05 & $(-0.85-0.75)$ & -0.57 & $(-1.07--0.07)$ & -0.45 & $(-1.02-0.11)$ \\
\hline \multicolumn{9}{|l|}{ Annual household income in Indian Rupees (RP) } \\
\hline$<60,000 \mathrm{RP}(<$ USD \$1500) & Ref. & & Ref. & & Ref. & & Ref. & \\
\hline $60,000-120,000$ RP (USD $\$ 1500-3000)$ & -0.58 & $(-1.21-0.05)$ & -0.58 & $(-1.23-0.06)$ & -0.57 & $(-1.02--0.12)$ & -0.50 & $(-0.96--0.04)$ \\
\hline$>120,000 \mathrm{RP}(>$ USD $\$ 3000)$ & -0.21 & $(-1.06-0.64)$ & -0.10 & $(-0.98-0.78)$ & -0.36 & $(-0.96-0.25)$ & -0.10 & $(-0.73-0.52)$ \\
\hline Astigmatism $\geq 2.00 \mathrm{D}$ in both eyes & -1.00 & $(-1.66--0.34)$ & -0.99 & $(-1.68--0.30)$ & -0.68 & $(-1.15--0.21)$ & -0.72 & $(-1.21--0.23)$ \\
\hline Anisometropia $\geq 1.00 \mathrm{D}$ & -0.19 & $(-0.96-0.59)$ & -0.23 & $(-1.03-0.57)$ & 0.29 & $(-0.26-0.84)$ & 0.38 & $(-0.19-0.95)$ \\
\hline Pupil size $\geq 4 \mathrm{~mm}$ & -0.42 & $(-0.86-0.03)$ & -0.31 & $(-0.77-0.16)$ & -0.35 & $(-0.67--0.03)$ & -0.34 & $(-0.66--0.01)$ \\
\hline Presenting vision worse than $20 / 63$ in the better eye & 0.30 & $(-0.13-0.72)$ & 0.42 & $(-0.02-0.87)$ & 0.17 & $(-0.14-0.47)$ & 0.25 & $(-0.06-0.57)$ \\
\hline Intercept & - & & 2.75 & $(0.57-4.94)$ & & & 1.93 & $(0.38-3.48)$ \\
\hline
\end{tabular}

$\mathrm{Cl}=95 \%$ Confidence Interval, USD = United States Dollars, $\mathrm{D}=$ diopters 
Figure 1.

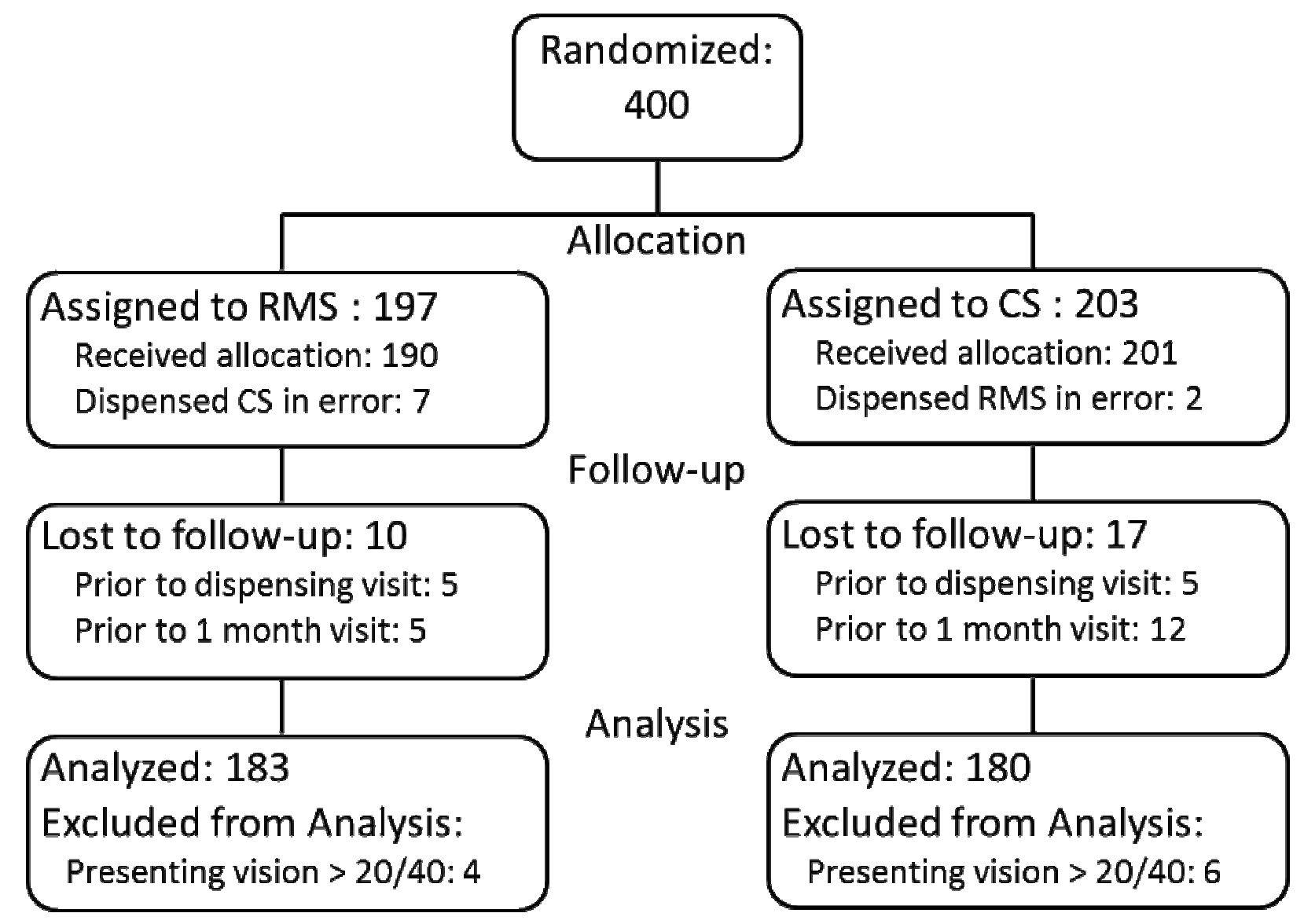


Figure 2.

Rasch scores at baseline

$$
(p=0.567)
$$

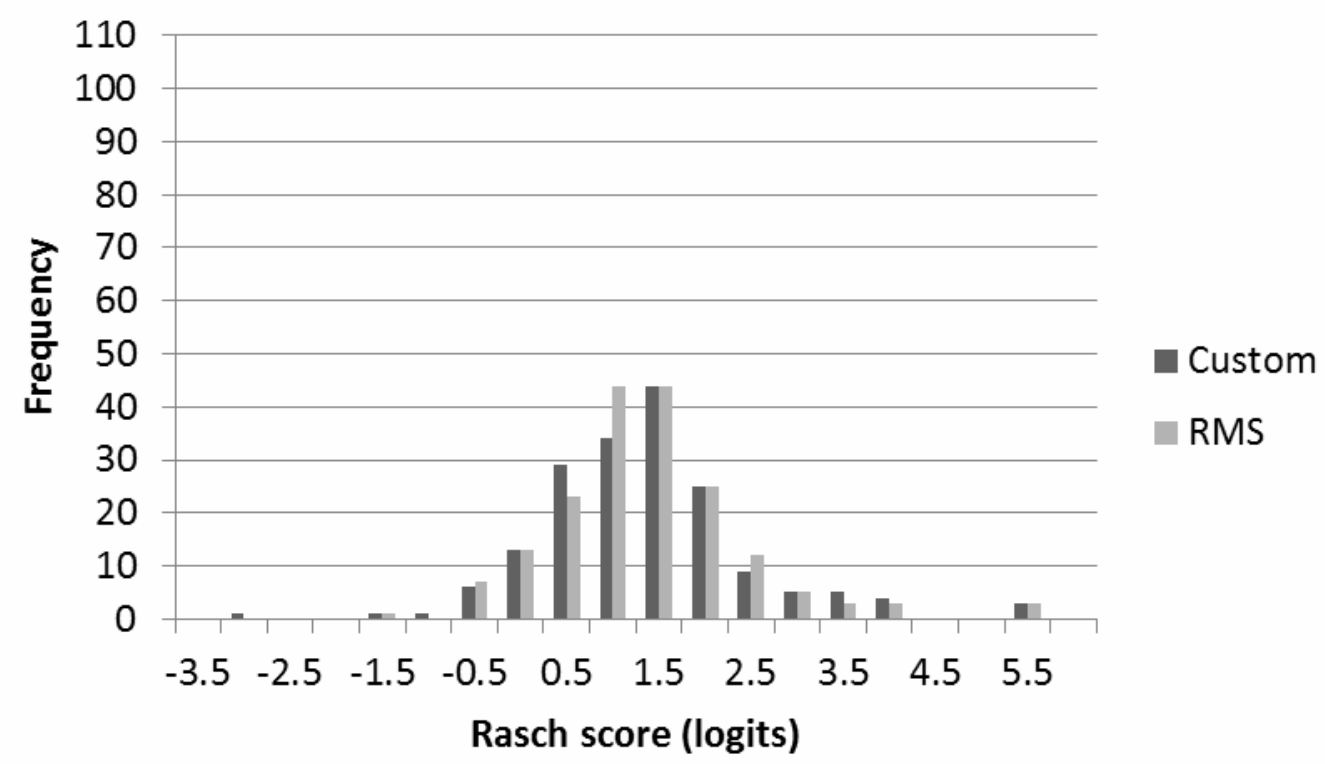

Rasch scores at follow-up

$(p=0.600)$

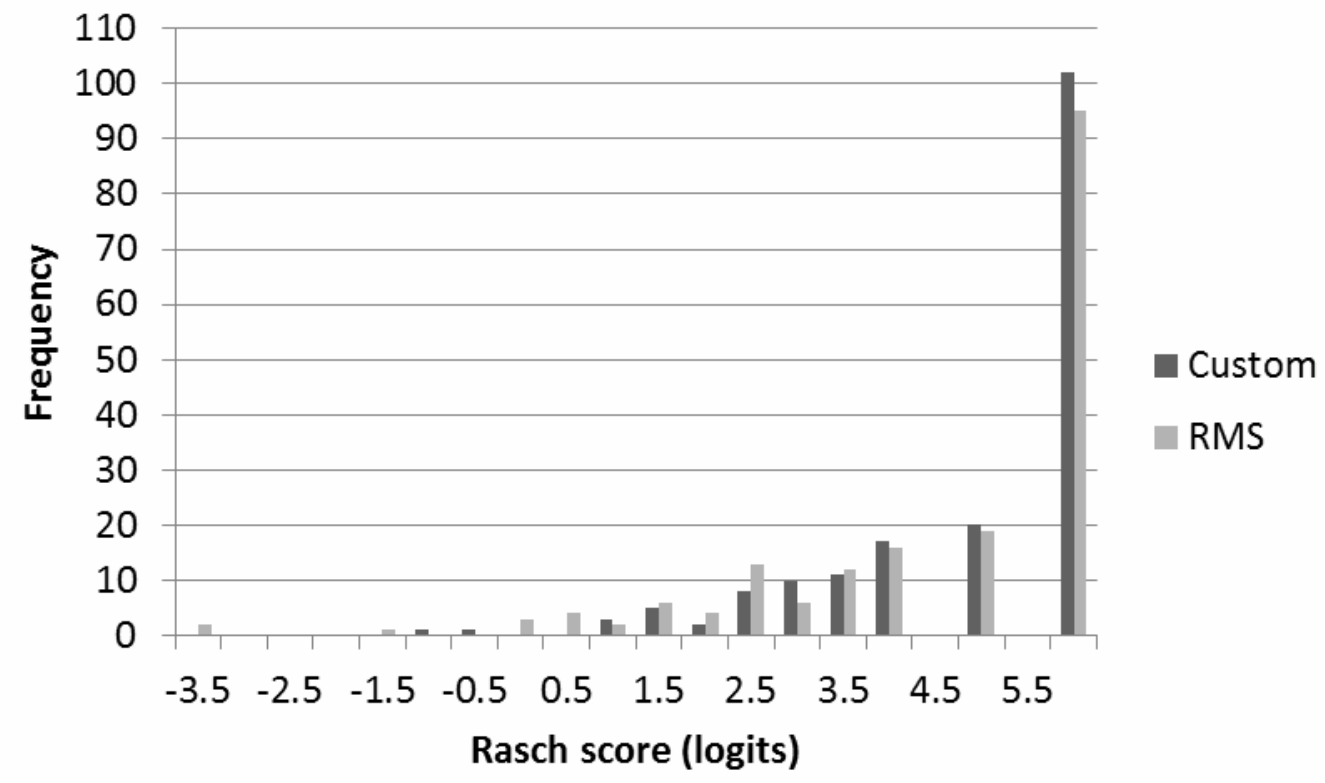


Figure 3.

Change in Rasch scores and change in visual acuity from baseline to follow-up

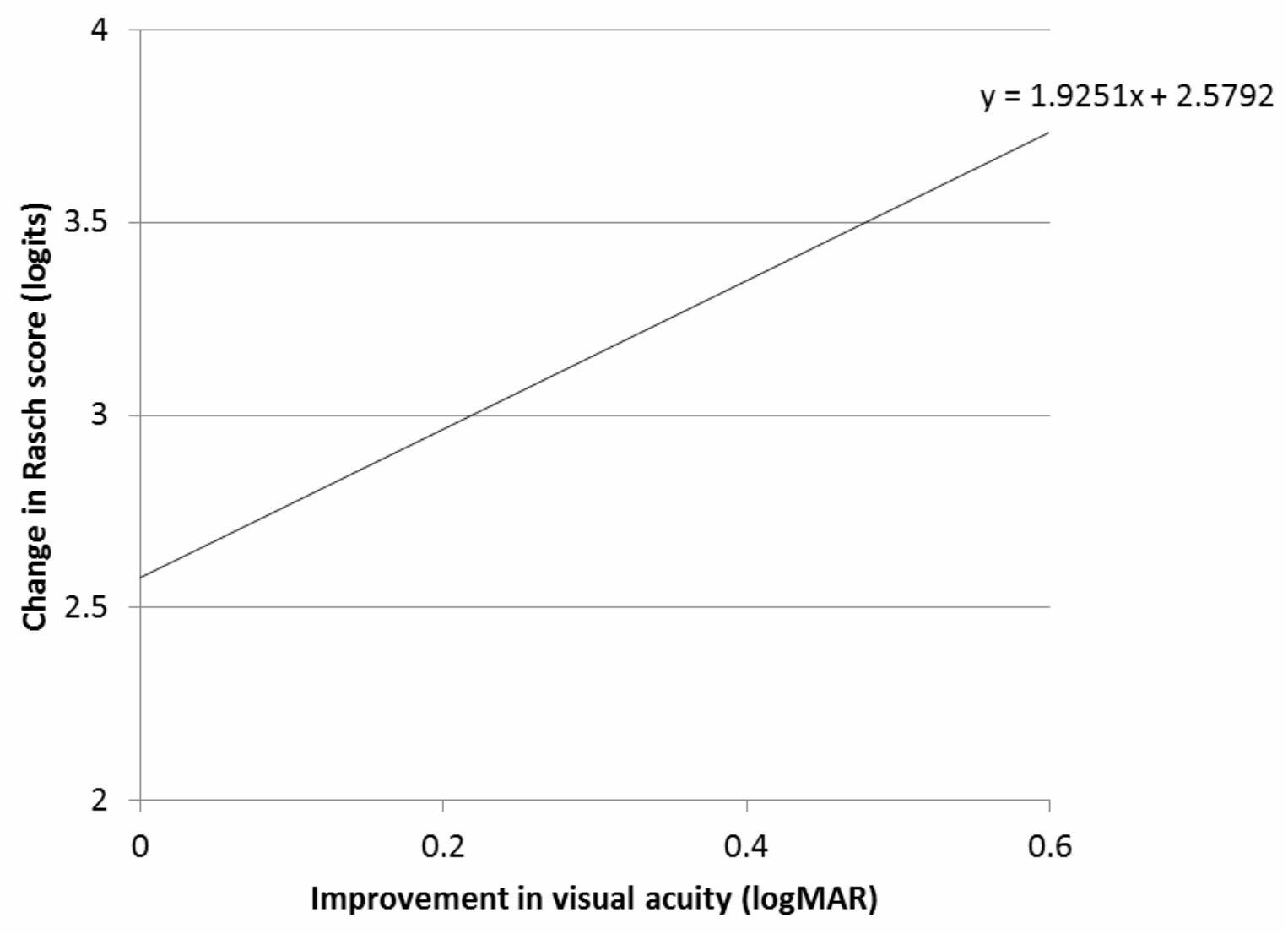




\section{Legends}

Figure 1. Flow chart of study participants progress through the clinical trial. RMS = ready-made spectacles, CS = custom spectacles.

Figure 2. Rasch scores at baseline and follow-up, by group. RMS = ready-made spectacles.

Figure 3. Change in Rasch scores and visual acuity from baseline to follow-up ( $n=363)$. A change of 0.1 logMAR in visual acuity (one line Snellen acuity), was associated with a 2.71 logit increase in Rasch score over the study period. logMAR = logarithm of the minimal angle of resolution. 